\title{
Review of Training Research Consultants: $A$ Guide for Academic Libraries
}

\author{
Lauren McMillan \\ Georgia Southern University
}

\begin{abstract}
Review of Torreano, J., \& O'Kelly, M. (Eds.) (2020). Training research consultants: A guide for
academic libraries. Chicago: Association of College and Research Libraries.
\end{abstract}

Keywords: information literacy, student employment, research consultants, peer research

consultants, peermentors

(c)

This is an Open Access article distributed under the terms of the Creative Commons Attribution 4.0 International License (http://creativecommons.org/licenses/by/4.0), which permits unrestricted use, distribution, and reproduction in any medium, provided the original work is properly cited. 
At over 400 pages, Training research consultants: A guide for academic libraries is an expansive guide for academic libraries of all sizes, public and private. While most of this book contains case studies of libraries' and writing centers' development and use of research consultants using peer learning, perspectives for peer research consultants themselves, and campus collaborators, provide different perspectives on the value of research consultants. Editors Jennifer Torreano and Mary O'Kelly offer insights into the effective use of peer learning, providing both practical and theoretical guidance. Overall, this is an excellent resource for academic libraries developing or improving programs

As Knowledge Market Manager at Grand Valley State Libraries, Jennifer Torreano begins by providing a background for using research consultants to successfully enhance the traditional roles of librarians in academic settings and provide a collaborative learning space. Torreano describes her experience in developing research consultant programs and emphasizes the need for continued training opportunities, both with professionals and among peers, rather than a one-off training program. Educational and library science theory are detailed to reflect how William Perry's theory of intellectual and ethical development, in conjunction with the Framework for Information Literacy, serve as a basis for utilizing research consultants. Self-efficacy is a major factor in the research consultant training process as a means of improving understanding and thus teaching of research methods to peers.

The typical barriers to effective library research are addressed, such as information overload and library anxiety, and how peer learning can overcome these barriers, many times more effectively than students having to approach a professional librarian for assistance. One important factor in having a varied approach to student learning is the concept that colleges and universities consist of more than just "traditional students" who have the same learning behaviors. Widely accepted constructivist and social learning theory suggest the benefit of developing programs where peers, in conjunction with professionals, can reach a wider audience than either can in isolation. 
Following the theoretical introduction are 14 case studies from colleges and universities with reflective descriptions and analyses of how their individual peer consultant programs function. The reflections included for each case study help identify where programs succeeded or failed which offers readers an opportunity to see how each program might fit into one's own institutional culture. Some of the most useful tools in the book are the appendices for each case study that include training policies, documents, and worksheets that can be directly adapted to individual needs. The resources included in the appendices vary in specificity and scope and therefore provide a diverse collection of tools that can be followed step-by-step or used as a guideline. Training research consultants is published under a creative commons license for non-commercial sharing and adapting. Readers can comfortably reuse the materials with attribution, a feature that is increasingly valuable among educators and demonstrates the purpose of including the insights from 15 different institutions.

After the case studies, there are three viewpoints from groups that collaborated with Grand Valley State's training for research consultants: the Center for Writing, the Speech Lab, and the User Experience team. Including these perceptions offers a window into the holistic, approach Torreano and O'Kelly describe from the beginning: a robust research consultant program does not occur or succeed in a vacuum. This provides a groundwork for considering what other departments have in common with utilizing students as peer teachers. There is some overlap in developing a peer consultant model among these areas, and similar resources for hiring and training are included as they were in the case studies.

Finally, two perspectives from research consultants are included at the end to highlight the student focus of the training programs detailed throughout the book. Both reflections express the selfefficacy that occurred as a result of the in-depth, continual training. The peer research consultants remarked on their own academic confidence that came from assisting peers with their research needs. It 
would be interesting to have quantitative data reflecting the peer teaching experience in order to gain a wider view of students' perceptions.

Whether you are at an institution with an existing peer research consultant program or one interested in creating one, Training research consultants can help layout a plan for establishing an effective program, both within the library and through partnerships among student support departments. 